\title{
Supporting information: Carbon Materials with Unusual Morphologies and Their Formation Mechanism
}

Qiang Liu, Zhi-Min Cui, Zhuo Ma, Shao-Wei Bian, Wei-Guo Song*

Beijing National Laboratory of Molecular Sciences (BNLMS)

Institute of Chemistry, the Chinese Academy of Sciences, Beijing 100080, P. R. China

Wei-Guo Song: wsong@iccas.ac.cn;

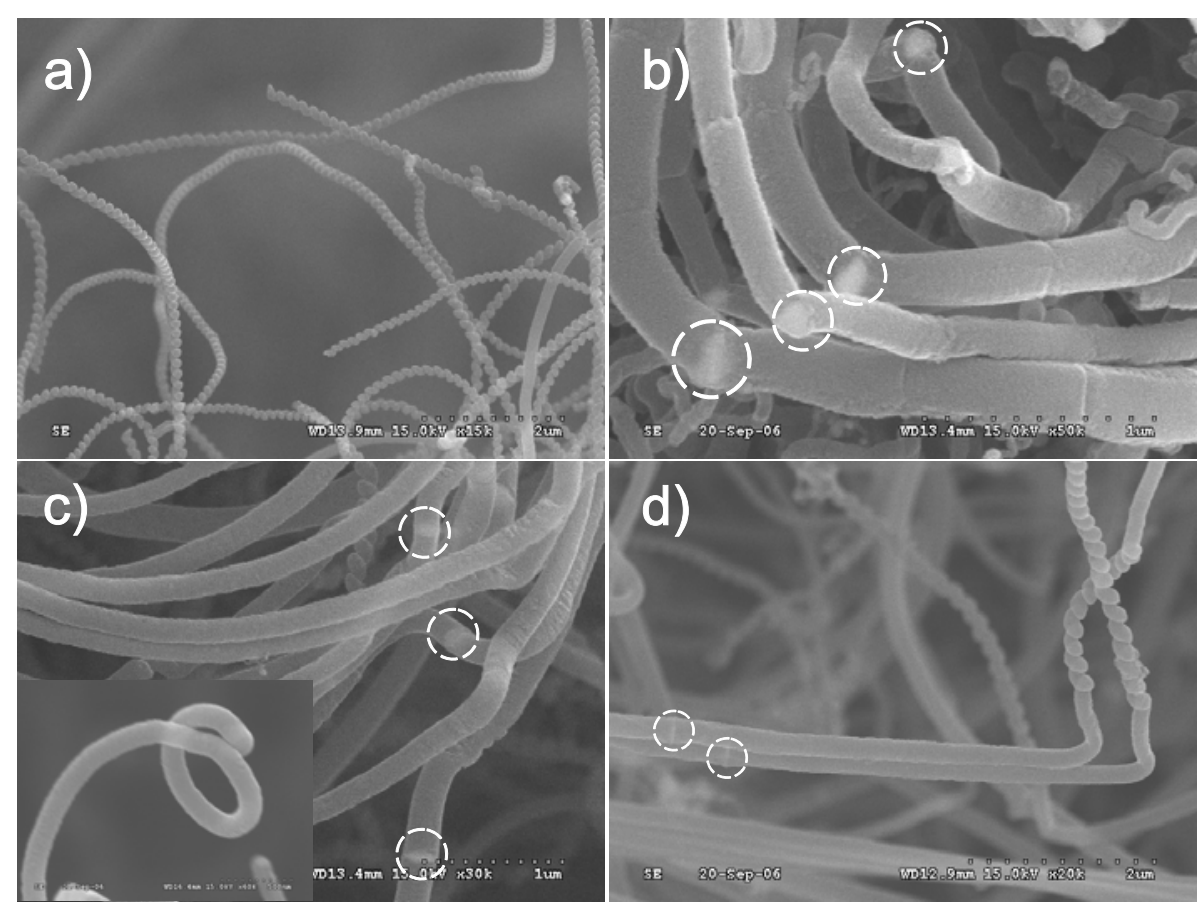

Figure S1. SEM images of the carbon products obtained at $550{ }^{\circ} \mathrm{C}$ under different acetylene delivery pattern on $95 \% \mathrm{Al}_{2} \mathrm{O}_{3}$ Ceramic substrate. a) Continuous acetylene flow for 10 minutes; b) 10 acetylene pulses; c) 5 acetylene pulses followed by acetylene flow for 10 minutes, inset in c) shows enlarged image of the tip of the carbon material; d) 5 minutes break between two continuous 10 minutes acetylene flows. 


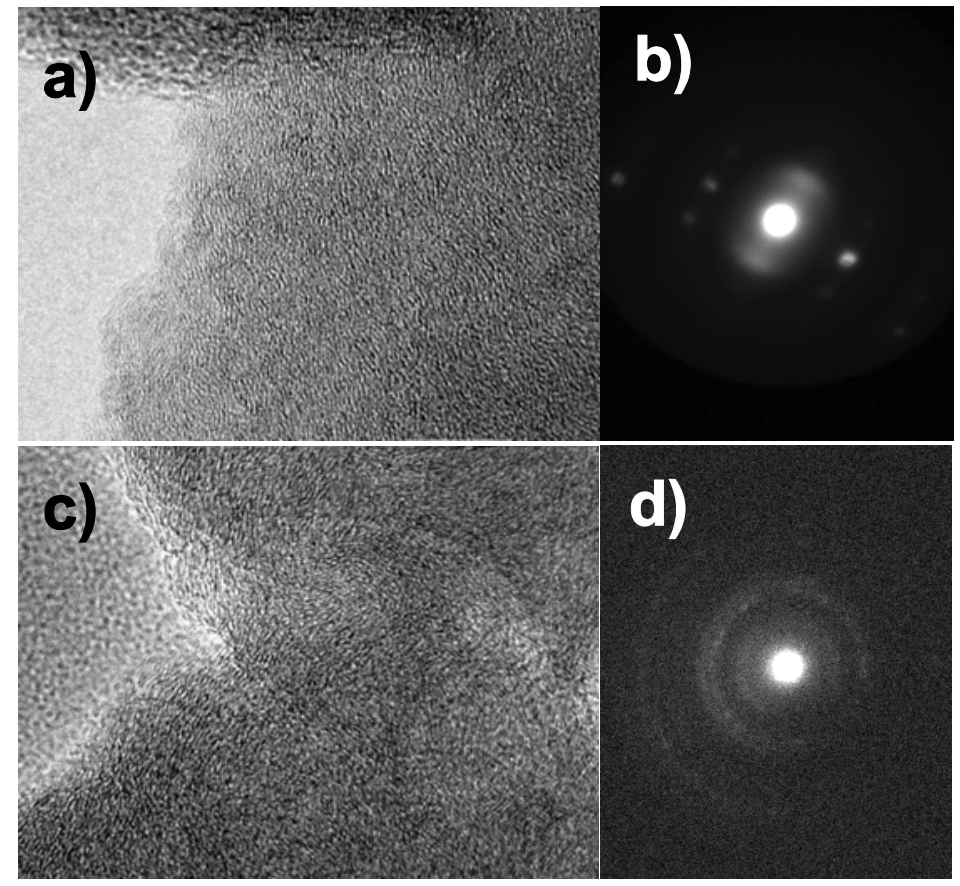

Figure S2. HRTEM and SAED images of CNCs and straight CNFs obtained in different reactive conditions at $550{ }^{\circ} \mathrm{C}$. a)\&b) continuous reaction; c)\&d) pulse reaction.

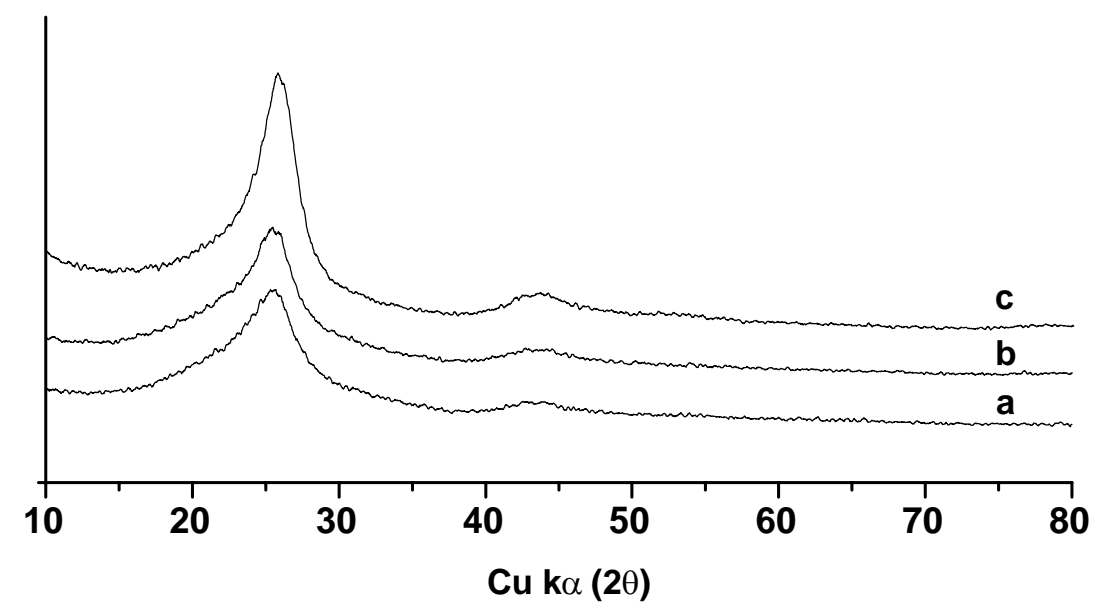

Figure S3. The XRD pattern of as-synthesized products obtained at a) $470{ }^{\circ} \mathrm{C}$; b) $550^{\circ} \mathrm{C}$; c) $580^{\circ} \mathrm{C}$. 


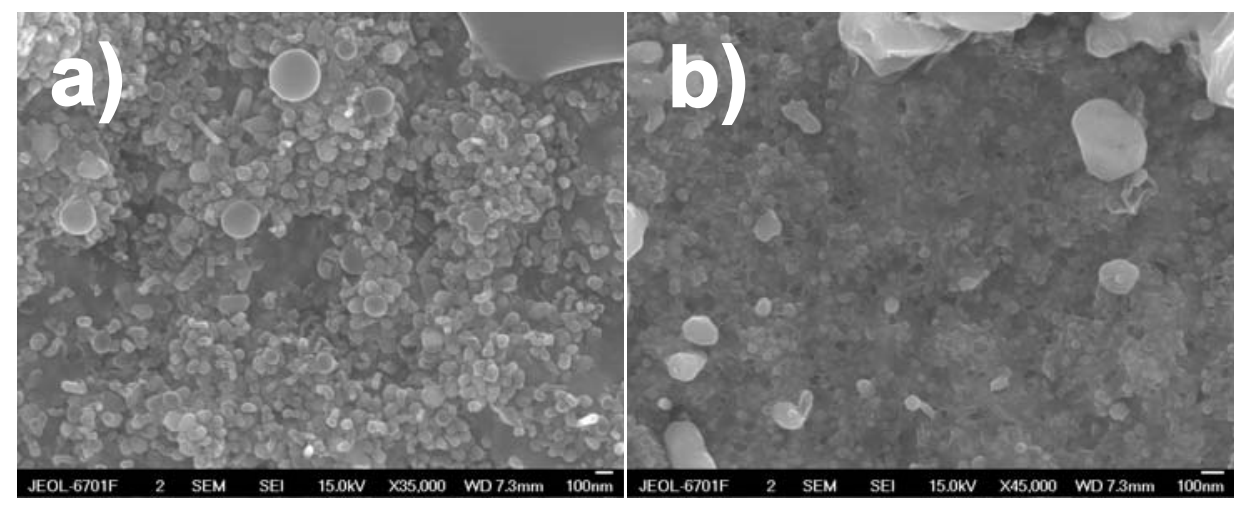

Figure S4. SEM images of the Ni catalyst obtained before reaction. a) without silicon pretreatment; b) with silicon pretreatment. 